\title{
PERANCANGAN SISTEM ADMINISTRASI DAN CATATAN REKAM MEDIK PASIEN PADA KLINIK PUTRI HUSADA
}

\author{
Inggrit Khoirunnisa ${ }^{1}$, Andi Dwi Pangestu ${ }^{2}$, Eddy Saputra ${ }^{3}$ \\ Program Studi Teknik Informatika, Fakultas Teknik dan Ilmu Komputer, \\ Universitas Indraprasta PGRI \\ Jalan Raya Tengah No 80, Kelurahan Gedong, Pasar Rebo, Jakarta Timur \\ inggrit.khoirunnisa@gmail.com ${ }^{1}$, andi.dwipangestu@gmail.com ${ }^{2}$, saputra2578@ gmail.com ${ }^{3}$
}

\begin{abstract}
Abstrak
Tujuan dari penelitian adalah untuk meningkatkan kinerja bagian administrasi dengan cara menggantikan sistem manual menggunakan sistem komputerisasi. Metode penelitian yang digunakan pada penelitian ini adalah metode grounded (grounded research). Grounded research yang merupakan metodologi penelitian kualitatif dimana data lapangan yang menjadi landasan penelitian. Selain metode grounded, peneliti juga menggunakan metode observasi, wawancara, dan studi pustaka dalam pengumpulan data-datanya. Program ini dibuat dengan menggunakan perangkat lunak Netbeans IDE 8.2, XAMPP, dan MySQL sebagai databasenya. Setelah peneliti melakukan analisa dan pembuatan aplikasi administrasi dan catatan rekam medik pasien, maka peneliti dapat mengambil kesimpulan bahwa aplikasi yang dibuat dapat menyajikan informasi klinik yang dibutuhkan oleh pengguna sehingga pelayanan administrasi klinik dapat lebih cepat, efektif dan efisien.
\end{abstract}

Kata Kunci: Sistem Administrasi, Rekam Medik, Klinik, Java, MySQL

\begin{abstract}
The purpose of the research was to improve the performance of the administration in a way to replace the manual system to computerized. The used method for the research was grounded method (grounded research). Grounded research is qualitative research methodology where the data field that became base for the research. Beside the grounded method, researchers also using the observation interview and literature review for collecting the data. The program was made with software Netbeans IDE 8.2, XAMPP, and MySQL as the database. After the researchers doing an analysis and making the administration application and patients medical record, researchers can take the conclusion that, the application was made can presents clinic information needed by the user so the administration of the clinic can be more quickly, effective and efficient.
\end{abstract}

Keywords: Administration System, Medical Record, Clinic, Java, MySQL.

\section{PENDAHULUAN}

Klinik merupakan fasilitas pelayanan kesehatan umum untuk memberikan perawatan kepada pasien. Klinik membutuhkan keberadaan sistem informasi yang akurat dan cukup memadai untuk meningkatkan pelayanan kesehatan terhadap pasien. Pengelolaan data pasien merupakan salah satu komponen penting dalam sebuah sistem informasi di klinik. Penyelenggaraan sistem informasi administrasi pada klinik masih menggunakan sistem pencatatan manual. Dalam penggunaan sistem manual segala pemrosesan data dilakukan oleh manusia dengan bentuk pencatatan sehingga peluang terjadinya kesalahan akan semakin besar. Dalam sistem administrasi pada klinik Putri Husada meliputi proses pendaftaran pasien, pencatatan rekam medik, dan pengajuan pengambilan obat. Dalam penyelenggaraan administrasi pendaftaran pasien, jika ada pasien yang tidak membawa kartu berobat akan kesulitan dalam pencarian data sehingga proses administrasi kurang efektif dan efisien. Pada saat pencatatan rekam medik pasien masih menggunakan kertas dan tidak memiliki salinan sehingga kekhawatiran akan kehilangan data besar. Menurut Mulyani (2017) "Perancangan sistem adalah penentuan proses dan data yang diperlukan oleh sistem baru". Sistem adalah kumpulan atau himpunan dari unsur atau variabelvariabel yang saling terkait, saling berinteraksi, dan saling tergantung satu sama lain untuk mencapai tujuan (Tohari, 2014). Menurut Jogiyanto dalam Tohari (2014) "Sistem adalah kumpulan elemen-elemen yang berinteraksi untuk mencapai suatu tujuan tertentu". Menurut 
Sugiarti (2018) " $U M L$ merupakan skema representasi grafis yang banyak digunakan secara luas untuk pemodelan sistem berorientasi objek".

\section{PENELITIAN RELEVAN}

Hasil penelitian terdahulu dapat dipakai sebagai acuan untuk melakukan penelitian selanjutnya. Meskipun ada perbedaan pada objek atau variabel yang diteliti, penelitian tersebut dapat dijadikan sebagai gambaran bagi peneliti berikutnya untuk melakukan penelitian. Penelitian yang dilakukan oleh (Herbowo Tri Nugroho, 2012) Analisis dan Perancangan Sistem Informasi Pelayanan Kesehatan pada Klinik Sahabat Insani Sleman dengan Menggunakan Java bertujuan untuk merancang dan membuat aplikasi sistem informasi pelayanan kesehatan berbasis desktop di Klinik Sahabat Insani.

Penelitian yang dilakukan oleh Sucipto, Indah Uly Wardati dalam jurnal Indonesia Journal on Networking and Security Vol: 4 Nomor: 02, April 2015, dengan judul Sistem Informasi Pendataan Pasien pada Rumah Bersalin dan Balai Pengobatan Pelayanan Kesejahteraan Umat (PKU) Muhammadiyah Batuwarno. Penelitian ini bertujuan.untuk mengembangkan sistem informasi pendataan pasien rawat jalan. Kesimpulan yang dapat diperoleh dalam penelitian ini adalah dengan adanya sistem informasi ini diharapkan mempermudah petugas dalam bekerja sehingga meningkatkan proses kinerja karyawan rumah sakit, dengan adanya sistem informasi ini pendataan pasien terhindar dari kerangkapan data.

\section{METODE PENELITIAN}

Metode penelitian yang digunakan oleh peneliti dalam penelitian ini adalah metode grounded (grounded reseacrh) yang merupakan sebuah metodologi penelitian kualitatif yang menekankan penemuan teori dari data observasi empiric di lapangan dengan metode induktif (menemukan teori dari sejumlah data), generatif (penemuan atau konstruksi teori menggunakan data sebagai evidensi), konstruktif (menemukan konstruksi teori atau kategori lewat analisis dan proses mengabstraksi), dan subyektif (merekontruksi penafsiran dan pemaknaan hasil penelitian berdasarkan konseptualisasi masyarakat yang dijadikan subjek studi). Dalam penelitian grounded research metode yang digunakan adalah studi perbandingan yang bertujuan untuk menentukan seberapa besar suatu masalah tersebut berlaku untuk umum. Untuk teknik pengumpulan data, peneliti mendapatkan data melalui observasi, wawancara, dan studi pustaka. Pada metode observasi, peneliti melakukan pengamatan dan pencatatan guna untuk mengumpulkan data. Peneliti mengamati bagaimana sistem berjalan pada proses administrasi yang terjadi di klinik. Dalam metode wawancara, peneliti melakukan tanya jawab secara lisan terhadap pihak-pihak yang terlibat yaitu pimpinan klinik dan petugas administrasi. Data penunjang yang diperoleh peneliti menggunakan metode studi pustaka dalam penelitian ini berasal dari buku, jurnal, skripsi yang serupa dengan penelitian yang akan dibuat.

\section{HASIL DAN PEMBAHASAN}

Pada saat pendaftaran pasien, pasien memberikan data diri kepada bagian administrasi. Bagian administrasi dapat melakukan pendaftaran pasien pada sistem komputerisasi yang telah dibuat. Kemudian pasien akan diperiksa oleh dokter dan okter akan mencatat keluhan pasien hingga terapi pasien dalam formulir rekam medik yang nantinya akan diberikan kepada bagian administrasi. Kemudian bagian administrasi akan menyalinnya pada sistem yang sudah terkomputerisasi agar dokumen tidak hilang. Ketika bagian administrasi sudah mendapatkan catatan rekam medik dari dokter dan sudah menyalinnya kedalam komputer, kemudian bagian adminitrasi dapat membuatkan kartu untuk pasien yang bertujuan untuk penebusan obat kepada bagian kasir. Bagian administrasi juga akan membuatkan laporan bulanan kepada penanggung jawab klinik yang nantinya akan dirapatkan dengan pimpinan klinik. Untuk lebih jelasnya mengenai alur sistem dapat dilihat pada diagram-diagram dibawah ini:

\section{Use Case Diagram}

Use Case Diagram merupakan penggambaran kebutuhan sistem dari sudut pandang pengguna(user) guna memperlihatkan hubungan antara actors dengan use case dalam sistem. Pada aplikasi ini terdapat 3 aktor yang terlibat yaitu admin, pasien, dan penanggung jawab klinik. 
Dimana admin dapat login kedalam sistem untuk mengelola data pasien, data dokter, data obat, transaksi rekam medik, transaksi kartu, dan laporan.

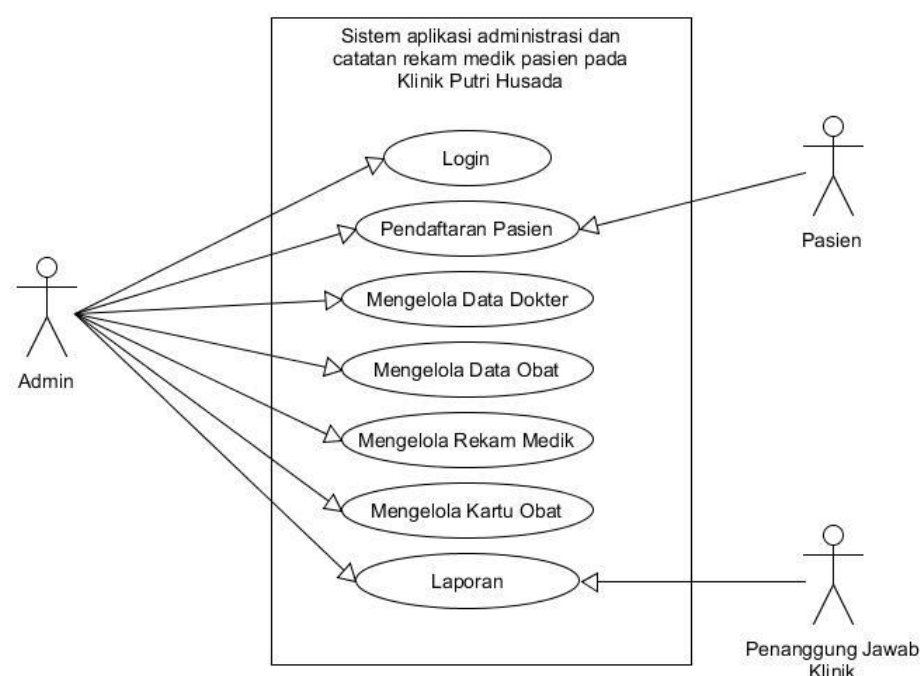

Gambar 1. Use Case Diagram

\section{Activity Diagram}

Activity Diagram adalah suatu gambaran tentang aktifitas yang terjadi dalam suatu proses tunggal.

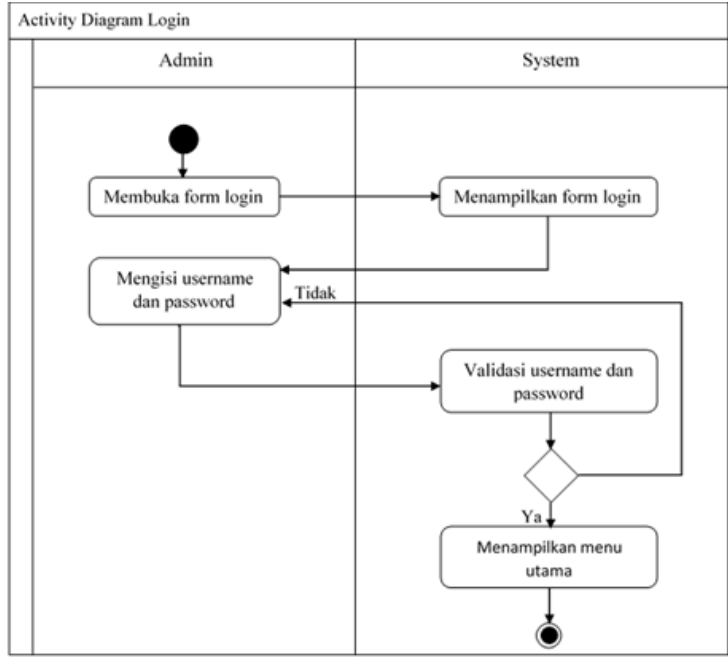

Gambar 2. Activity Diagram Login

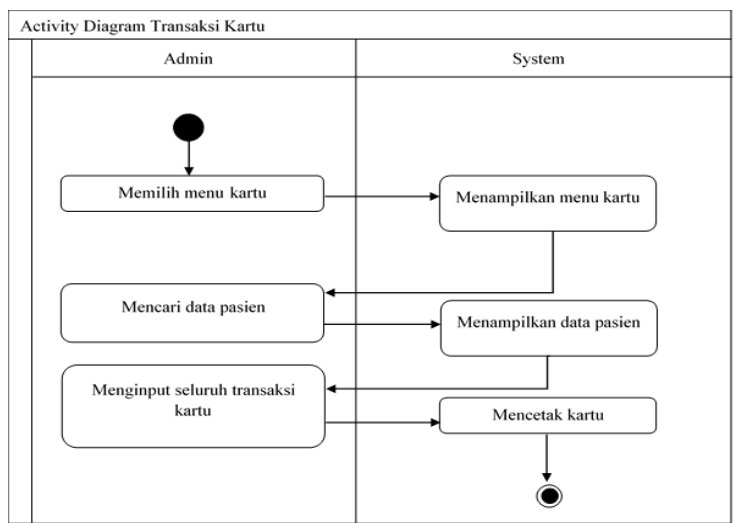

Gambar 3. Activity Diagram Transaksi Kartu 


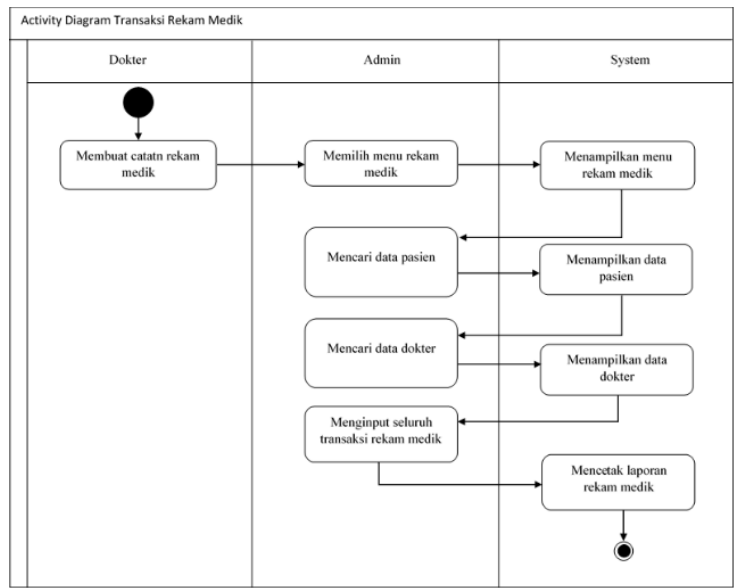

Gambar 4. Activity Diagram Transaksi Rekam Medik

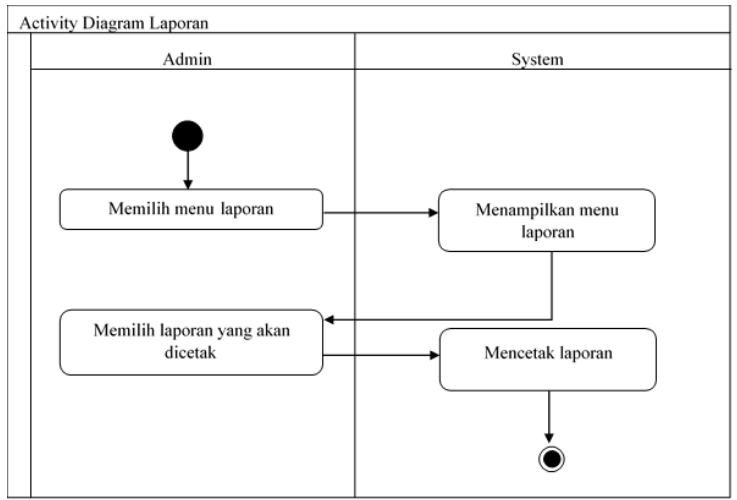

Gambar 5. Activity Diagram Laporan

Class Diagram

Class Diagram berguna untuk menjelaskan database yang terdapat dalam program.

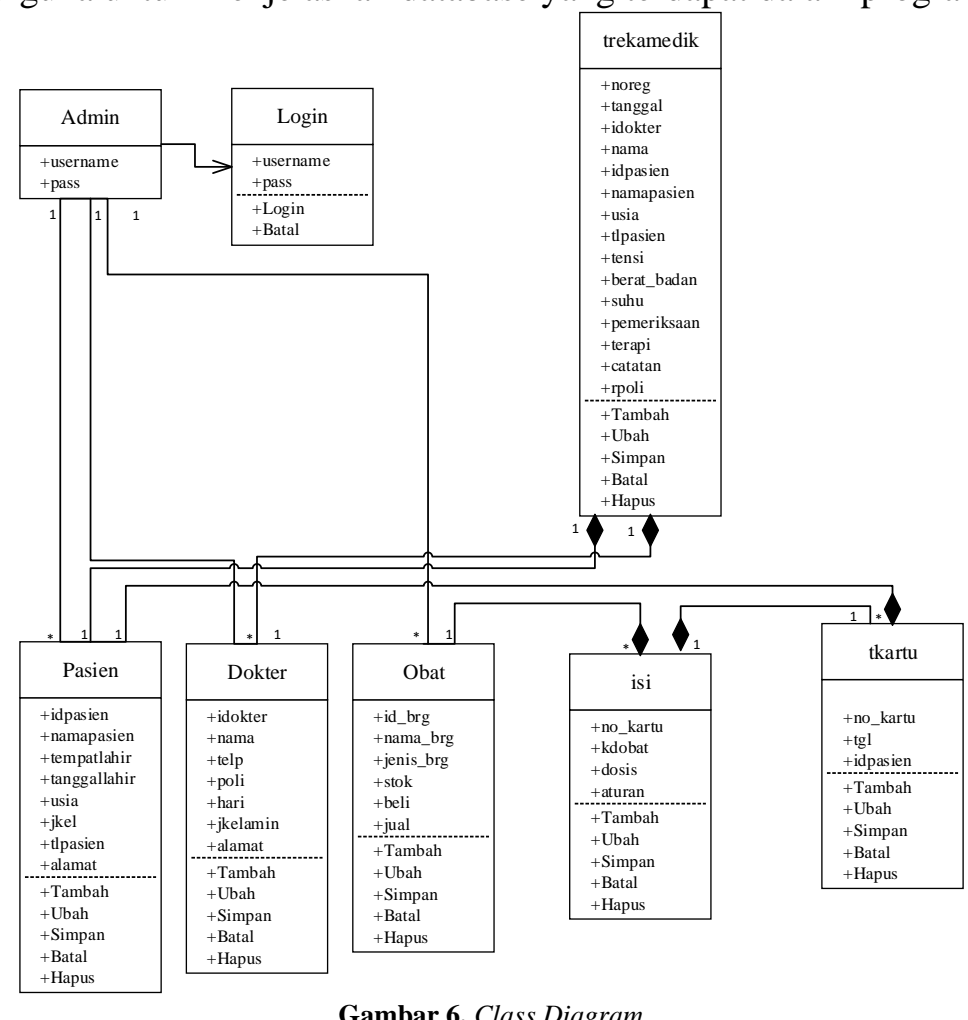




\section{Implementasi}

Implementasi program dilakukan dengan menggunakan metode Black Box. Metode black box testing merupakan pengujian program yang mengutamakan pengujian terhadap kebutuhan fungsi dari suatu program yang dibuat. Didalam penelitian ini, peneliti menggunakan laptop Intel Core i53337 u $1.8 \mathrm{Ghz}$, memory RAM 4GB dengan Harddisk 548GB dengan tujuan agar proses running pada aplikasi dapat berjalan dengan baik.

\section{Pengujian Program}

Pengujian black box dilakukan dengan cara memberikan sejumlah input pada program. Input kemudian diproses sesuai dengan kebutuhan fungsional untuk melihat sesuai atau tidaknya hasil output dengan yang diingingkan dan sesuai tidaknya fungsi dari program tersebut. Jika output sudah sesuai dengan kebutuhan maka program yang dibuat sudah benar. Jika output belum sesuai, maka masih terdapat kesalahan pada program tersebut dan akan dilakukan perbaikan terhadap kesalahan program.

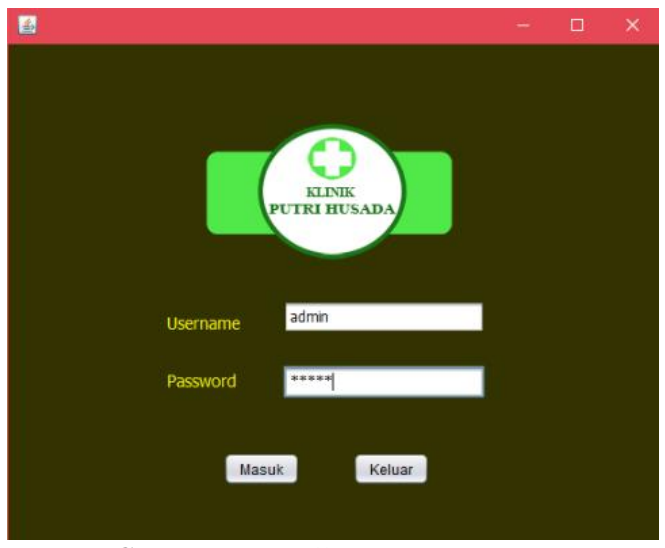

Gambar 7. Tampilan Menu Login

Tampilan form login yang berisikan username dan password ini berguna untuk masuk kedalam aplikasi

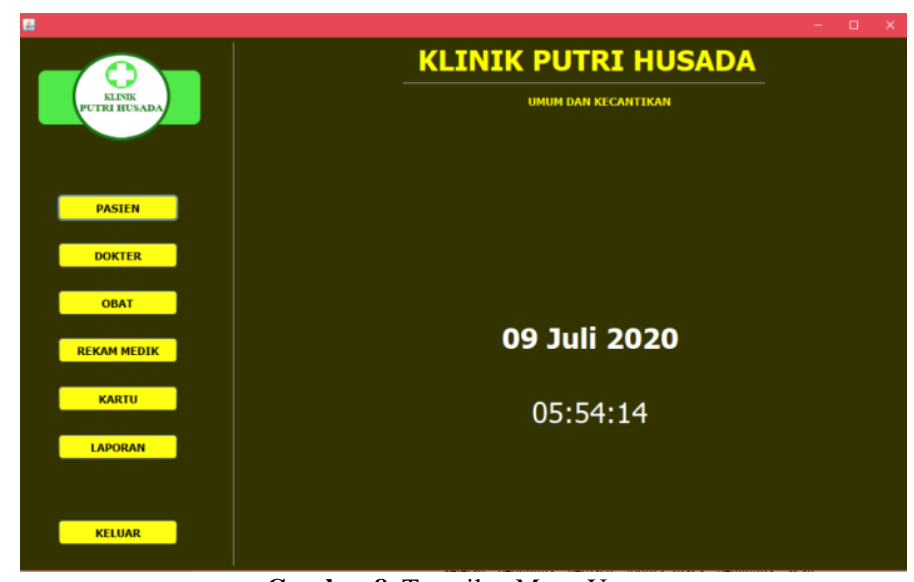

Gambar 8. Tampilan Menu Utama

Setelah pengguna berhasil login, maka pengguna akan diarahkan kemenu utama. Tampilan menu utama berisikan pilihan menu seperti menu pasien, menu dokter, menu obat, menu rekam medik, menu kartu untuk pengambilan obat, menu laporan guna memberikan laporan bulanan, dan menu keluar yang nantinya akan kembali lagi ke halaman login. 


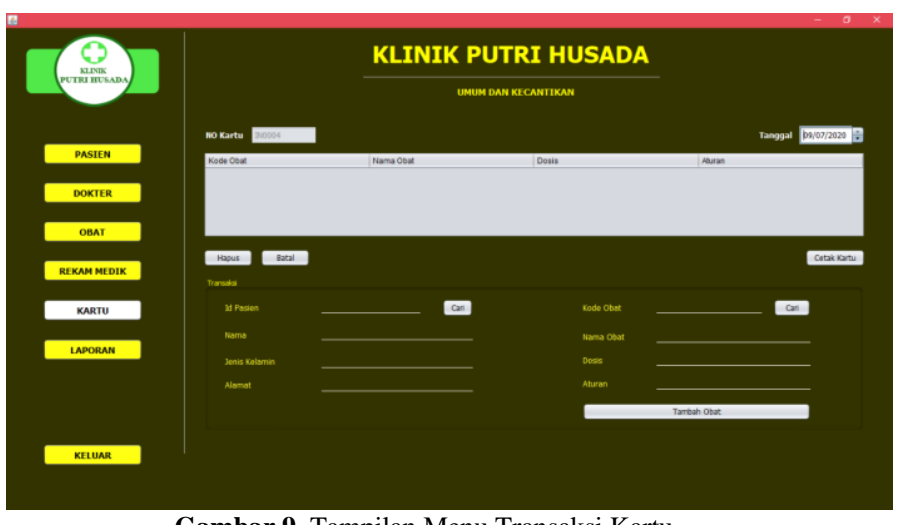

Gambar 9. Tampilan Menu Transaksi Kartu

Pada gambar diatas merupakan menu tampilan transaksi kartu. Menu transaksi kartu berguna untuk mencetak kartu pengambilan obat.

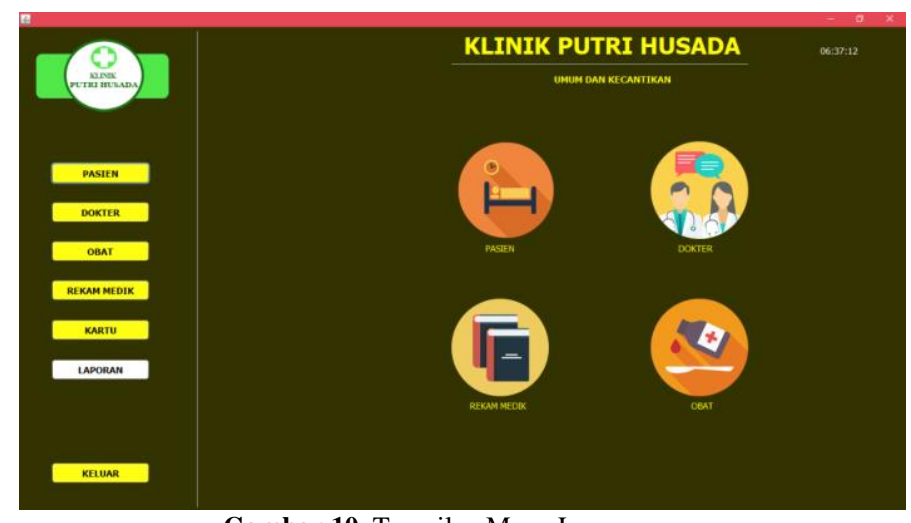

Gambar 10. Tampilan Menu Laporan

Menu laporan disini berguna untuk mencetak kegiatan administrasi yang ada diklinik. Jika ingin mencetak data pasien yang pernah berobat diklinik maka pengguna dapat memilih menu "pasien". Jika ingin mencetak data dokter, pengguna dapat memilih menu "dokter". Jika ingin mencetak data obat, pengguna dapat memilih menu "obat". Dan jika ingin mencetak laporan rekam medik yang berguna untuk menganalisis kebutuhan obat klinik, maka pilih menu "rekam medik".

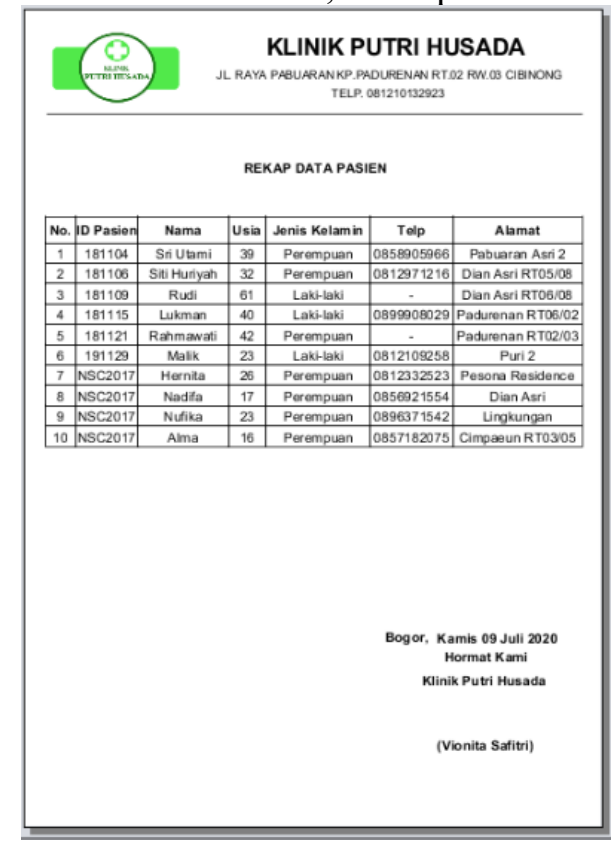

Gambar 11. Tampilan Menu Laporan Data Pasien

Tampilan laporan rekap data pasien ini berisi data-data pasien yang ada pada klinik dan bagian administrasi akan menyerahkan laporan ini setiap bulannya. 


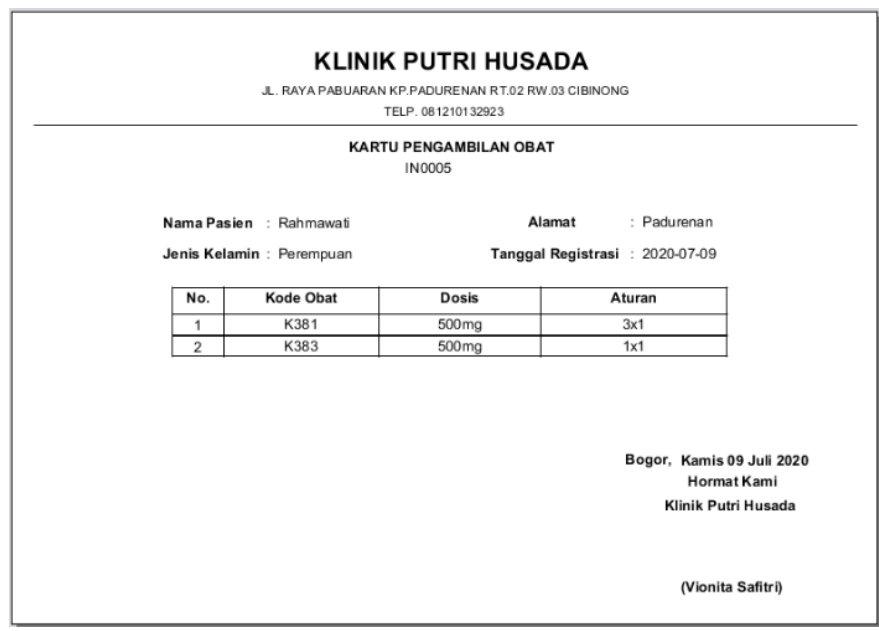

Gambar 12. Laporan Kartu Pengambilan Obat

Tampilan laporan kartu pengambilan obat berisi informasi pasien dan informasi obat yang akan diterima oleh pasien.

\section{SIMPULAN}

Berdasarkan analisa yang dilakukan, maka perancangan sistem administrasi dan catatan rekam medik pasien pada Klinik Putri Husada dapat diterapkan. Dilihat dari rumusan masalah dalam penelitian, peneliti mempunyai kesimpulan pada penelitian ini yaitu aplikasi yang dibangun dapat menyajikan informasi klinik yang dibutuhkan oleh pengguna, seperti data pasien, data dokter, data obat, data rekam medik. Pelayanan administrasi pada klinik jauh lebih cepat, efektif, dan efisien dikarenakan sudah terkomputerisasi. Sistem informasi yang telah dibangun dapat membantu memudahkan bagian administrasi dalam mencari data yang dibutuhkan.

\section{DAFTAR PUSTAKA}

Enterprise, J. (2015). Kumpulan Aplikasi Java. Elex Media Komputindo.

Haqi, B., Kom, M., \& Setiawan, H. S. (2019). Aplikasi Absensi Dosen Dengan Java dan Smartphone Sebagai Barcode Reader. Elex Media Komputindo.

Lubis, A. (2016). Basis Data Dasar. Deepublish.

Mathar, I. (2018). Manajemen Informasi Kesehatan: Pengelolaan Dokumen Rekam Medis. Deepublish.

Mulyani, S. (2017). Metode Analisis dan Perancangan Sistem. Abdi Sistematika.

Oktafianto, M. M. (2016). Analisis dan Perancangan Sistem Informasi Menggunakan Model Terstruktur dan UML. Yogyakarta: CV Andi Offset.

Sanjaya, W. (2012). Media komunikasi pembelajaran. Jakarta: Kencana Prenada Media Group.

Sugiarti, Y. (2018). Dasar-dasar pemrograman JAVA Netbeans, Database, UML, dan Interface. Bandung: PT. Remaja Roskadarya.

Tohari, H. (2014). Analisis Serta Perancangan Sistem Informasi Melalui Pendekatan UML. Yogyakarta: CV Andi Offset. Yakub, J. B. (2012). Pengantar Sistem Informasi. Graha Ilmu. 